\title{
Breves Considerações em Torno da Estrutura e Função da Fórmula com Cláusula Arbitrária no Processo Romano Clássico
}

\author{
Luiz Carlos de Azevedo \\ Professor Assistente Doutor de Direito \\ Processual Civil na Faculdade de Direito da \\ Universidade de São Paulo.
}

1. Em outra oportunidade, já havíamos ressaltado o enorme significado do direito pretoriano, cuja principal atribuição consistiu em completar, suprir e interpretar as lacunas da lei, corrigindo, ainda, o rigor de seus efeitos, os quais, por vezes, resultavam em flagrante iniquidade ou prejuízo considerável para as partes.

Mas, conforme então lembrávamos, com a gradativa expansão da República, os pretores urbanos já não mais se apresentavam suficientes para atender aos inúmeros problemas que se sucediam, razão porque se instituiram outros, peregrinos, com jurisdição sobre os litígios postos entre cidadãos romanos e estrangeiros. (242 A.C.) A esta altura, distinguiam-se, também, dois juízos: os legítimos onde o juiz romano decidia, em Roma, ou até a uma milha da cidade, conflitos de interesses entre cidadãos romanos: e os chamados "judicium imperium continentia", atendidos pelo pretor peregrino, - por constituirem função e poder de seu "imperium" - envolvendo questões onde, pelo menos uma das partes, não era romana.

Em tais casos, como desconheciam as partes o direito, bem agia o pretor por fornecer como também ao juiz, uma instrução por escrito; aproveitando o sistema, com sucesso, nas províncias, veio ter, com o tempo, à metrópole, dele resultando as chamadas "fórmulas", cuja importância foi de tal modo relevante, que acabou por dar nome ao período.

2. Assim, assumiu característica fundamental do processo formular, a instrução que o pretor fornecia ao juiz, para que este julgasse a causa que the fora submetida.

Mas a palavra fórmula há de ser examinada em dois sentidos: no primeiro, a fórmula modelo, constante do edito 
do pretor, disposição colocada "in abstracto" e dirigida a todos ; no segundo, de maneira mais específica, a fórmula "judicium", aplicada ao caso concreto, isto é, a processo determinado, onde já se designavam os seus dados principais, tais como o nome do juiz e das partes, a importância pretendida ou o bem reclamado: ao contrário do antigo sistema das ações da lei, onde tudo transcorria oralmente, figurava, agora, uma recomendação por escrito, redigida pelo magistrado, após oitiva sumária das partes e na qual vinham esclarecidos os pontos de direito, bem como os fatos que o juiz devia levar em conta ao proferir sua decisão.

Em tal conformidade, enquanto no edito, a fórmula não passa de paradigma estabelecido em caráter geral a respeito da eventual questão ocorrente, desde o momento em que esta realmente surge, a fórmula adquire vida, funcionando como instrução escrita para aquele caso concreto, agindo exclusivamente naquele processo que está para ser julgado.

3. GAIo, na sua objetividade quase que lacônica, enuncia as quatro partes essenciais da fórmula, "demonstratio", "intentio", "adjudicatio", "condemnatio", (Inst. 4.39) passando, a seguir, a defini-las e a fornecer alguns exemplos de cada qual.

Continham as fórmulas, entretanto, outros elementos, essenciais e acessórios: antes da "demonstratio", vinha a designação do juiz incumbido de prolatar a sentença, "nominatio judicis"; além disto, em certos casos, inseriam-se a "praescriptio pro actore" ou "pro reo", substituida esta, depois, pela "exceptio"; e, ainda, a "replicatio", resultante da "exceptio" alegada pelo réu, a "duplicatio", a "treplicatio"

Enquanto na "demonstratio" se achava contida, em linguagem moderna, a causa do pedido, isto é, descreviam-se, embora sucintamente, os fatos e fundamentos jurídicos do pedido, - "quod Aulus Agerius de Numerio Negidio hominem vendidit" - a "intentio" traduzia a pretensão do demandante, onde o autor "desiderium suum concludit": "si paret $\mathrm{N}$. Negidium A. Agerio sestertium X milia dare oportere" (Inst. 4,40 e 41).

Existiam fórmulas que se resumiam na "intentio": era o caso das "actiones praejudiciales", ações que se destinavam a obter o reconhecimento de um fato que serviria de fundamento à outra ação; diziam respeito ao estado das pessoas, ao direito de família, aos bens patrimoniais; nelas, encontraria a doutrina moderna o conceito da ação meramente declaratória. 
A vantagem da ação prejudicial residia na circunstância de tornar o fato indiscutível quando julgado por sentença; e não é outro o proveito no direito atual, pois se a apreciação de questão prejudicial não faz coisa julgada quando levantada pelo réu, na contestação, ou quando incluída pelo juiz, na motivação de sua sentença, forçosamente o fará, quando provocada e proferida em ação declaratória incidental (art. 470 do Código de Processo Civil).

Nestas ações, não havia falar em "condemnatio", pois o juiz se limitava a declarar, ou não, o direito pretendido; mas, de ordinário, nas demais ações, completava-se a fórmula com a condenação ou absolvição do réu: "judex N. Negidium A. Agerio sestertium X milia condemna; si non paret, absolve"; (Inst., 4,43) finalmente, incluía-se, em certas ações, a "adjudicatio", - ou esta substituia a "condemnatio" - quando se mostrava necessário transferir a propriedade da coisa para uma das partes (Inst. 4, 42)

4. Mas a condenação, no processo formulário, devia consistir, sempre, no pagamento de uma determinada quantia em dinheiro; este princípio era fundamental, atestando-o a lição de GaIo e os textos do Digesto: "A condenação, em todas as fórmulas que a contém, é concebida sob forma de avaliação em dinheiro. Assim, se pedirmos qualquer coisa corpórea, como um fundo, um escravo, uma roupa, ouro, prata, o juiz não condena o réu à prestação da própria coisa, objeto do litígio, como era costume fazer-se antigamente, mas o condena ao equivalente em dinheiro, depois de avaliada a coisa". (Inst. 4,48) "Ait praetor, condemnatus ut pecuniam solvat: a judicato ergo hoc exigitur, ut pecuniam solvat" (D. 42, 1, 4, 3).

Esta exigência, se portava utilidade, pois conferia ao autor o direito de obter o pagamento da condenação mesmo se a coisa litigiosa houvesse desaparecido no curso da demanda, isto é, entre a "litiscontestatio" e a sentença, trazia, por outro lado, vários inconvenientes; com efeito, às vezes, a pretensão do demandante se situava na restituição de um bem específico e determinado, de sua propriedade, não lhe interessando a substituição em pecúnia; por isto, em se tratando, por exemplo, de objeto de estimação do autor, é evidente que este não via satisfeito seu anelo com o recebimento do equivalente em moeda corrente, mesmo porque a quantia não lhe iria trazer de volta o bem que se achava fora da esfera de seu patrimônio e que, malgrado ganhasse a ação, não lhe seria devolvido. Da mesma forma, nas obrigações de fazer, o que o demandante realmente desejava era a execução da tarefa contratada, não lhe parecendo 
suficiente o simples pagamento da quantia fixada pelo juiz na sentença.

E não era só, pois ocorria, ainda, outro estorvo: com a "listiscontestatio", dera-se uma "novatio" necessária, pela qual a anterior obrigação de direito material fora substituída por uma obrigação de direito processual; de tal sorte, o credor não possuía mais crédito ao bem, mas crédito ao dinheiro que deveria ser pago pelo devedor; se, antes da condenação, este se tornava insolvente, ficava aquele na contingência de arcar com os azares de um indesejado concurso de credores.

Para obviar todos estes embaraços à pretensão do demandante, costumava-se colocar na fórmula, uma cláusula pela qual se determinava que a condenação pecuniária não incidiria caso o réu restituísse ou exibisse a coisa pleiteada (Inst. 4, 163). Em tais hipóteses, o juiz, após afirmar o direito do autor, mas antes de atingir a condenação, ou melhor, como prejudicial desta, possibilitava ao réu a restituição da coisa: será condenado, a não ser que restitua. Se o réu atendia a determinação, o processo aí se encerrava; não acatada a ordem, aquele prosseguia, culminando com a sentença condenatória.

O exemplo clássico da fórmula com cláusula arbitrária provém de Cícero: "L. Octavius judex esto: sí paret, fundum Capenatem, quo de agitur ex jure Quiritum P Servilii esse, Neque Is Fundus Q. Catulo Restituetur (II actio contra Verres, lib. II, XII, 31).

Buscava-se, assim, com a alternativa da restituição em espécie, a imediata e precisa satisfação da pretensão do autor. $\mathrm{E}$, para compelir o réu a devolver ou exibir, estabelecia-se, também, que o valor da coisa devia ser estimado, sob juramento, pelo próprio autor; isto é, ainda que o valor da causa fosse assentado pelo juiz, permitia-se ao autor, sob juramento estimatório, avaliar a quantia correspondente ao bem pretendido. Ora, esta faculdade conferia ao demandante, embora sob juramento, a prerrogativa de estimar à coisa um alto valor, trazendo, por conseqüência, condenação majorada no caso do seu não cumprimento pelo demandado.

Por isto, às vezes, com vistas a coibir os naturais exageros da estimativa, limitava o juiż o juramento até quantia certa, mais consentânea com o valor real do bem, mas, de qualquer forma, sempre mais onerosa para o condenado. (D. 12, 3, 5).

Interessante observar: séculos passados, quando da recepção do Direito Romano na Europa continental, - ou melhor, quando de seu redescobrimento - o juramento 
estimatório vai aparecer, em Portugal, nas Ordenações Afonsinas, Liv. III, Tít. 91, 2, alí constando que se o vencedor quiser haver somente a verdadeira valia da coisa, poderá jurar aos Santos Evangelhos, e segundo o que afirmar, assim será o réu condenado; mas o seu juramento tem limite, não podendo ir além da avaliação fixada, de antemão, pelo julgador.

Atualmente, a doutrina veio criar condições bastantes para coartar o devedor da obrigação a satisfazê-la em espécie, isto é, sem que fosse reduzida ao correspondente montante em pecúnia ou resolvida em perdas e danos; as "astreintes" do direito francês e, entre nós, as medidas coercitivas, tais como a multa estabelecida por dia de atraso, quando do descumprimento do contrato, são exemplos dignificativos da solução adotada; (artigos 644 e 645 do Código de Processo Civil) tais cláusulas, como se sabe, visam obter - "adimplemento da obrigação pela prestação do próprio executado, compelido a cumpríla para evitar as pesadas sanções que o ameaçam".

Pois isto acontecia, sob certa forma, também no processo romano, por força do que dispunha a cláusula arbitrária; embora se dissesse que "quia non facit quod promisit, in pecuniam numeratam condemnatur", (D. 42,1,13,1) verdade é que a cláusula em exame continha o propósito de fornecer ao demandante, a satisfação plena, específica, de sua pretensão; isto é, diligenciava-se no sentido de que este não recebesse tão somente o valor em dinheiro, correspondente ao valor do bem pretendido, - ou, ainda, o valor correspondente à obrigação que o devedor avençara realizar - mas, isto sim, a própria coisa, objeto do pedido formulado.

Em razão do préstimo alcançado, difundiu-se o emprego da cláusula arbitrária entre as ações tanto reais quanto pessoais: na "reinvidicatio", na "hereditatis petitio", na "vindicatio pignoris", na "vindicatio servitutis ou usufructus", etc.; além destas, na "actio ad exhibendum", na "actio aquae pluviae arcendae", naquelas resultantes dos interditos restitutórios quando o possuidor se negava a acatar a ordem do pretor para a reintegração do bem; e, ainda, nas ações "quod metus causa", de "dolo malo", "noxalis", "de injuris", "fabiana, calvisiana, pauliana", "de eo quod certo loco", etc.

5. Há, na ordem jurídica, juízos de direito e juízos de equidade. Ademais, "jus est ars boni et aequi". (D. 1, 1, 1, pr.). A cláusula arbitrária, colocada nas fórmulas, nada mais pretendia senão encontrar uma solução de eqüidade, na qual o juiz, antes de condenar, servia como verdadeiro mediador 
entre as partes, propondo a restituição, a qual traria, por conseqüência, a absolvição do réu.

$\mathrm{E}$, por assim agir, estava-se atingindo, de maneira mais rápida e eficiente, aliada à melhor objetividade, apanágio dos romanos, a resolução do conflito de interesses colocado entre as partes.

\section{Bibliografia}

ANdRÉ GIfFard, Études de Droit Romain, Paris, 1972, p. 65.

Francesco BUonamici, Lo Storia della procedura civile romana, Roma, 1971, (1886) p. 140.

André Giffard, Précis de Droit Romain, Paris, 1951, p. 130.

Jean Gaudemer, Institutions de l'Antiquité, Paris, 1967, p. 622.

Ursicino Alvarez, Curso de Derecho Romano, Madrid, 1955, p. 411.

EDou'ARD CUQ, Institutions juridiques de romains, Paris, 1902, p. 740, vol. II.

RAYMOND MONIER, Manuel élémentaire de droit romain, Paris, 1947, (1970) vol. I, p. 176.

Vittorio Scialoj'A, Procedura civile romana, Roma, 1894, p. 179.

Humberto Cuenca, Processo Civil Romano, Buenos Aires, 1957, p. 69.

F. DE ZuluetA, The Institutes of Gaius, Oxford, 1953, p. 258 (II).

Jose Carlos Moreira Alves, Direito Romano, Rio, 1971, p. 235 do vol. I.

Luiz Carlos De Azevedo, O Direito de ser citado, S. Paulo, 1980, p. 118. 